Proceeding Paper

\title{
Long-Term Sensitivity Analysis of Palmer Drought Severity Index (PDSI) through Uncertainty and Error Estimation from Plant Productivity and Biophysical Parameters ${ }^{\dagger}$
}

\author{
Subhasis Ghosh ${ }^{1, *}$, Subhajit Bandopadhyay ${ }^{2, *}$ and Dany A. Cotrina Sánchez ${ }^{3}$ \\ 1 Department of Geography, Visva-Bharati University, Santiniketan 731235, India \\ 2 Department of Ecology and Environmental Protection, Poznan University of Life Sciences, Piatkowska 94, \\ 60-649 Poznan, Poland \\ 3 Instituto de Investigación para el Desarrollo Sustentable de Ceja de Selva (INDES-CES), \\ Universidad Nacional Toribio Rodríguez de Mendoza de Amazonas, Chachapoyas 01001, Peru; alexan- \\ der.cotrina@untrm.edu.pe \\ * Correspondence: mail.subhasis@yahoo.com (S.G.); subhajit.bandopadhyay@up.poznan.pl (S.B.) \\ + Presented at the 1st International Electronic Conference on Forests - Forests for a Better Future: Sustainabil- \\ ity, Innovation, Interdisciplinarity, 15-30 November 2020; Available online: https://iecf2020.sciforum.net.
}

Citation: Ghosh, S.; Bandopadhyay, S.; Cotrina Sánchez, D.A. Long-Term Sensitivity Analysis of Palmer Drought Severity Index (PDSI) Through Uncertainty and Error Estimation from Plant Productivity and Biophysical Parameters. Environ. Sci. Proc. 2021, 3, 57. https://doi.org/ 10.3390/IECF2020-07956

Academic Editors: Angela Lo Monaco, Cate Macinnis-Ng and Om P. Rajora

Published: 12 November 2020

Publisher's Note: MDPI stays neutral with regard to jurisdictional claims in published maps and institutional affiliations.

Copyright: (c) 2020 by the authors. Licensee MDPI, Basel, Switzerland. This article is an open access article distributed under the terms and conditions of the Creative Commons Attribution (CC BY) license (http://creativecommons.org/licenses /by/4.0/).

\begin{abstract}
Palmer Drought Severity Index (PDSI) is the most effective and well-acknowledged drought severity index that particularly determines the long-term drought conditions over the forest and other terrestrial ecosystems. However, the sensitivity of PDSI has not been explored yet based on productivity (i.e., Gross Primary Productivity (GPP)), biophysical parameters (i.e., biomass-Leaf Area Index (LAI) and Enhanced Vegetation Index (EVI) and greenness content-Normalized Difference Vegetation Index (NDVI)), and absorbed solar radiation by plants (i.e., fraction of Absorbed Solar Radiation (fAPAR)) over a humid-subtropical forest ecosystem. In this study, the sensitivity of the PDSI was analyzed through uncertainty and error estimation modeling from long-term (2015-2019) MODIS GPP and reflectance data using Google Earth Engine (GEE) over a humid-subtropical forest region of Arunachal Pradesh, India. It was experimentally observed that EVI was the most sensitive parameter to the PDSI in long-run observation based on a low uncertainty (2.39-3.01\%) and error (0.07-0.12) compared to the other parameters. Besides, EVI had a strong agreement with PDSI compared to GPP, NDVI, LAI, and fAPAR, where the Pearson's $\mathrm{r}$ ranged from -0.87 to -0.63 , except 2015 . Hence, it is stated that EVI is the simple, effective, and most complementary indicator for assessing the PDSI over the forest regions of a tropical ecosystem. This study showed that EVI might be a promising tool for effectively evaluating long-term drought impacts on the forest ecosystem that indicates the actual water deficit-induced stress conditions.
\end{abstract}

Keywords: Palmer Drought Severity Index; Enhanced Vegetation Index; forest; tropical ecosystem; Google Earth Engine; India

\section{Introduction}

Drought is the dryness condition of the environment that creates ecological stress due to lack of precipitation and shortages in water supply for plant growth. The Palmer Drought Severity Index (PDSI) [1] is one of the most effective, well-acknowledged, and widely used drought severity index that particularly determines the long-term drought conditions over the forest and other terrestrial ecosystems.

The PDSI is based on the demand and supply concept of the water balance model, taking consideration not only precipitation deficit but also includes local temperature and soil moisture anomalies to assess relative dryness [2]. Several studies were already 
conducted on the application of the PDSI; however, the sensitivity of the PDSI has not been explored yet based on productivity (i.e., Gross Primary Productivity or GPP), biophysical parameters (i.e., biomass - Leaf Area Index or LAI and Enhanced Vegetation Index or EVI and greenness content-Normalized Difference Vegetation Index or NDVI), and absorbed solar radiation by the plants (i.e., fraction of Absorbed Solar Radiation or fAPAR) over a humid-subtropical forest ecosystem. It was also observed that most of the existing literatures on drought severity preferred to use productivity, net photosynthesis (Gross Primary Productivity and Net Primary Productivity) [3-12], or NDVI or near-infrared (NIR) based vegetation indices [13-19] for long-term drought condition assessments. Hence, a true sensitivity analysis of all important vegetation parameters like GPP, NDVI, EVI, LAI, and fAPAR was necessary to find out the most complimentary and effective PDSI indicator that shows the actual water deficit-induced stress conditions over the vegetative areas of a subtropical humid ecosystem. In this study, the sensitivity of PDSI was analyzed through uncertainty and error estimation modeling from long-term (2015-2019) MODIS GPP and other reflectance products (NDVI, EVI, and LAI) and fAPAR using the open-source cloud-computing platform Google Earth Engine (GEE).

\section{Study Area}

The study was carried out over the humid-subtropical forest region of Arunachal Pradesh, India, the Indian state that is enriched with the second-largest forest cover spreading over $79.63 \%$ of the total geographical area of the state [20] (Figure 1). This north-eastern state lies at the Eastern Himalayan region of the country coordinated between $26^{\circ} 28^{\prime} \mathrm{N}$ to $29^{\circ} 30^{\prime} \mathrm{N}$ latitude and $91^{\circ} 30^{\prime} \mathrm{E}$ to $97^{\circ} 30^{\prime} \mathrm{E}$ longitude and shares international boundaries with Bhutan in the west, China to the north and northeast, and Myanmar to the east. The climate varies from temperate in the northern part and warm humid in the southern part, having annual rainfall ranging between $2000 \mathrm{~mm}$ to $8000 \mathrm{~mm}$ and annual temperatures from $<0{ }^{\circ} \mathrm{C}$ to $31^{\circ} \mathrm{C}$ [20].

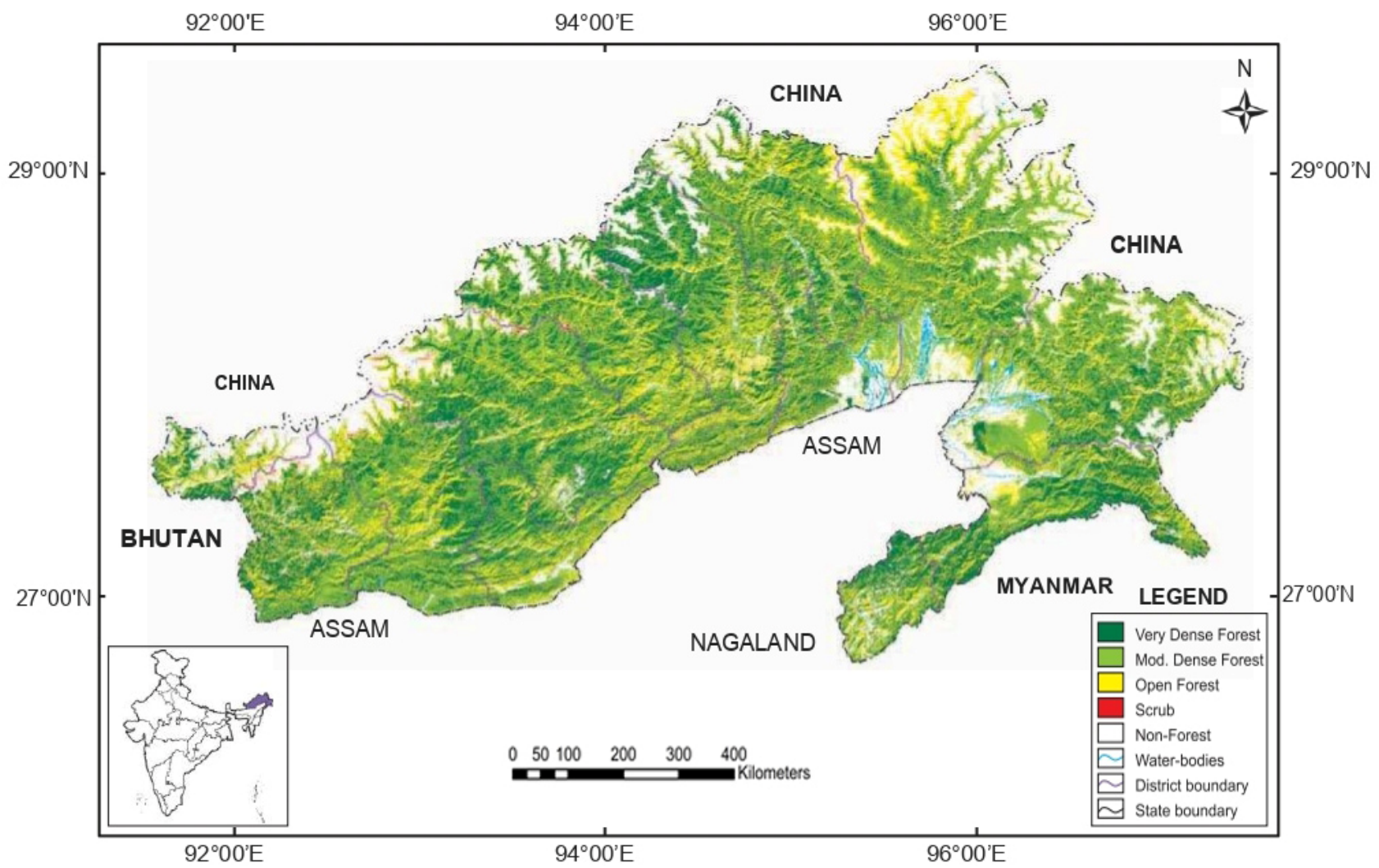

Figure 1. The forest cover map of Arunachal Pradesh, India (Source: India State of Forest Report 2019, Forest Survey of India, Ministry of Environment, Forest \& Climate Change, Govt. of India). 


\section{Materials and Methods}

\subsection{Dataset}

The monthly PDSI data (2015-2019) used in this study was obtained from TerraClimate products that provide monthly climate and climatic water balances for global terrestrial surfaces developed by the University of Idaho, USA [21]. Similarly, long-term (2015-2019) GPP products (MOD17) were obtained from a Moderate Resolution Imaging Spectroradiometer (MODIS) Terra sensor with the temporal resolution of 8 days. Other required vegetation parameters such as NDVI (MOD13Q1), EVI (MOD13Q1), LAI (MOD15A2H), and fAPAR (MOD15A2H) were also collected from the MODIS Terra sensor with the temporal resolutions of 16 days and 8 days respectively. The mean monthly products of GPP, NDVI, EVI, LAI, and fAPAR were developed through cloud computing using the GEE platform.

\subsection{Methodology}

\subsubsection{Development of PDSI}

PDSI was developed by Palmer in 1965 and uses readily available temperature and precipitation data, as well as the locally available water content of the soil, to estimate the relative dryness. The step-wise retrieval of PDSI was discussed by Palmer, 1965 [1]. It is a standardized drought index that spans -4 (extremely dry) to +4 (extremely wet). It has been reasonably successful at quantifying long-term drought, as it uses local temperature and rainfall data and a physical water balance model for estimation. It can also capture the basic effect of global warming on drought through changes in potential evapotranspiration. Monthly PDSI values do not capture droughts on time scales less than about 12 months.

\subsubsection{Development of Vegetation Parameters}

The sensitivity of the five most commonly used vegetation parameters (i.e., GPP, NDVI, EVI, LAI, and fAPAR) was tested with PDSI to understand the most sensitive parameter in reference to PDSI for the long term under tropical or humid-subtropical climatic contexts. GPP is the rate at which chemical energy (typically expressed as carbon biomass or organic substances) is created by primary producers through capturing solar energy in a given unit of area and time during photosynthesis. GPP is considered as a very useful indicator of drought conditions in terms of productivity, as reported by several studies that were mentioned before. LAI and EVI both indicate the biomass condition of vegetations. However, LAI ( $\mathrm{LAI}=$ leaf area/ground area, $\mathrm{m}^{2} / \mathrm{m}^{2}$ ) typically characterizes plant canopies, whereas EVI is highly responsive to plant physiognomy. EVI also indicates the water balance and atmospheric droughts of leaves that are the major eco-physiological parts of a plant that interact with the atmosphere. The formula used for computing EVI is

$$
E V I=G \times \frac{(N I R-R E D)}{(N I R+C 1 \times R E D-C 2 \times B L U E+L)}
$$

where NIR/red/blue are atmospherically corrected or partially atmosphere corrected (Rayleigh and ozone absorption) surface reflectance, L is the canopy background adjustment that addresses nonlinear, differential NIR and red radiant transfer through a canopy, and C1 and C2 are the coefficients of the aerosol resistance term, which uses the blue band to correct for aerosol influences in the red band. The coefficients adopted in the MODIS-EVI algorithm are; $\mathrm{L}=1, \mathrm{C} 1=6, \mathrm{C} 2=7.5$, and $\mathrm{G}$ (gain factor) $=2.5$. The NDVI $(N D V I=N I R-R E D / N I R+R E D)$ is a widely used greenness (chlorophyll content) indicator of vegetation, which is often used to assess the water deficit-induced stress levels in plants. Lastly, fAPAR is one of the essential climate variables recognized by the UN Global Climate Observing System (GCOS) that has great potential to monitor and assess drought impacts on vegetation. fAPAR monitors the greenness and health of vegetation 
by quantifying the fraction of the solar radiation absorbed by alive leaves for the photosynthesis activity.

\subsubsection{Data Conversion}

As the obtained data varied in terms of their temporal resolutions, data standardization was very much necessary for any kind of further analysis. "Naive" method of conversion [22] was used to convert the NDVI, EVI, LAI, and fAPAR data into their average monthly values that facilitated comparability with the monthly PDSI information.

\subsubsection{Statistical Measurements}

Sensitivities of all five vegetation parameters were measured individually in respect to PDSI using three different statistical methods: (1) agreement between parameters using Pearson's r, (2) error estimation between parameters, and (3) uncertainty estimation through Root Mean Squared Error (RMSE). Pearson's r showed the relationship between the response variable (i.e., vegetation parameters) and the explanatory variable (i.e., PDSI) and helped to understand the agreement between response and explanatory variables ranging between -1 (negative agreement) to +1 (positive agreement). Standard Error of the estimate (SEE) derived from Pearson's simple linear regression analysis was used for error estimation between the PDSI and the other vegetation parameters, as this statistic allows to construct a confidence interval within which the true population correlation will fall [23]. Hence, smaller values indicate better sensitivity. Lastly, the Root Mean Squared Error (RMSE) was used to assess the standard deviation of the prediction errors and to measure the uncertainty between variables. The lower values of RMSE indicated the low uncertainty between variables and vice versa. Open-source computing $(R$ studio, version: 3.6.1) was used for statistical calculations.

\section{Result and Discussion}

\subsection{Interpretation of Pearson's Correlation Analysis}

Figure 2 shows the spatiotemporal distribution of PDSI on the study region over time (2015-2019).

In Pearson's correlation analysis (Figure 3), EVI showed as the most promising indicator in the long-term agreement between vegetation parameters and PDSI. Pearson $r$ values for EVI was the highest negatively correlated parameter, with the PDSI ranging between -0.63 to -0.87 over the years (except 2015) in comparison to NDVI, GPP, LAI, and fAPAR. In 2015, EVI showed a surprisingly higher positive correlation with PDSI (0.50), which could be the result of the massive rainfall situation that hit the state of Arunachal Pradesh during that year [24]. Such a huge amount of rainfall effectively recharged the soil layers, which helped the forest region to overcome the water deficit conditions.

After EVI, the other vegetation parameters, i.e., LAI, NDVI, GPP, and fAPAR, respectively, were found to have high negative agreement with the PDSI. 

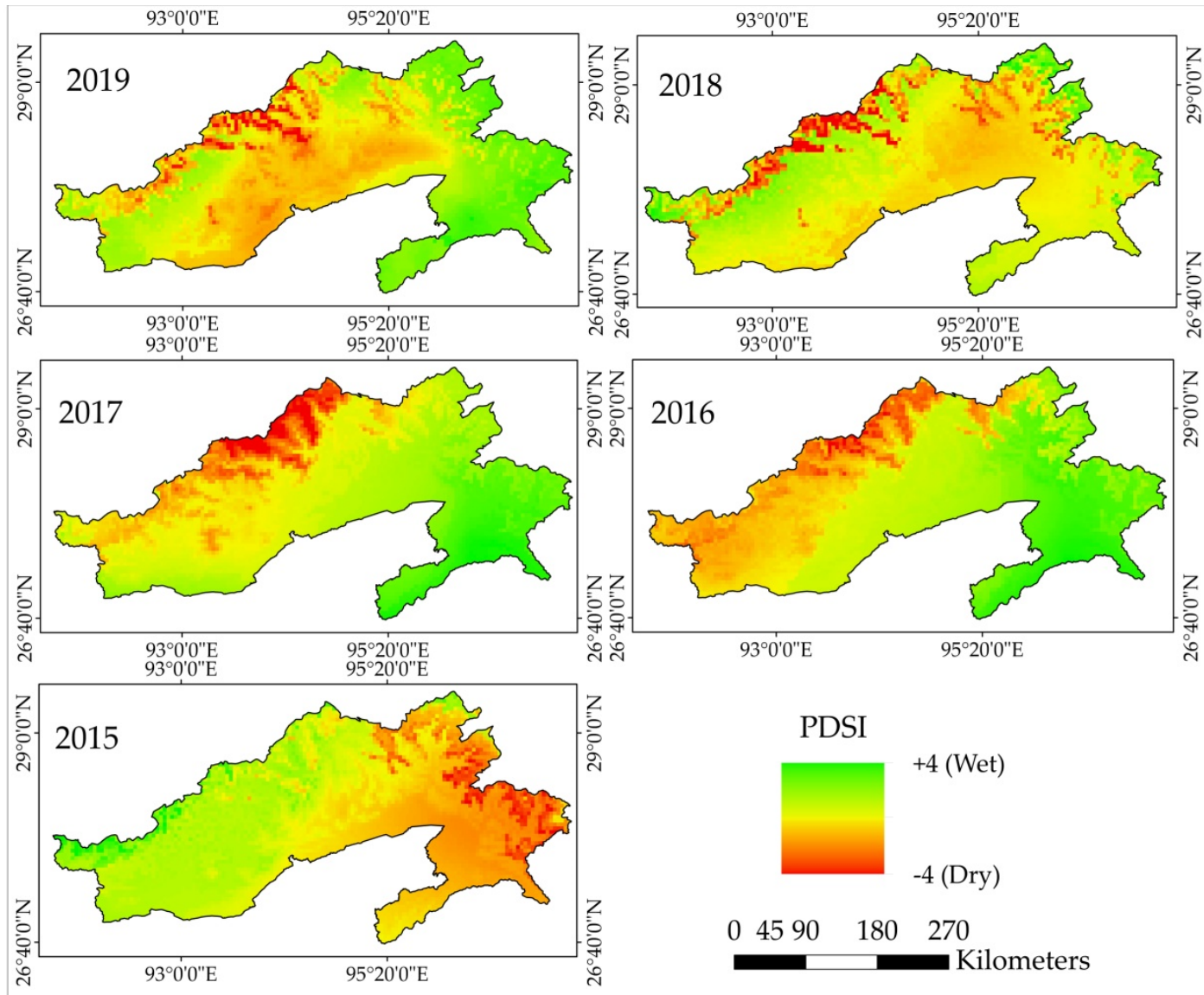

Figure 2. Temporal distribution (2015-2019) of the Palmer Drought Severity Index (PDSI) over Arunachal Pradesh, India. PDSI value -4 represents the dry conditions, and +4 represents the wet conditions.

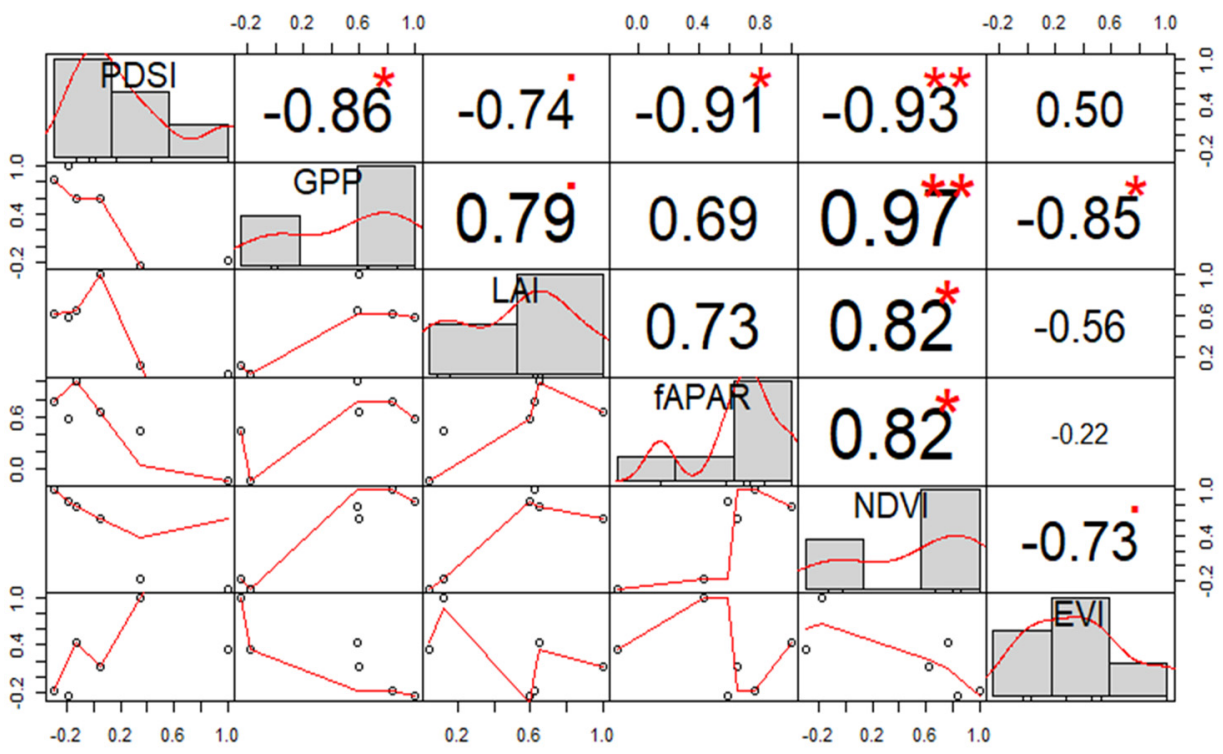

(a) 


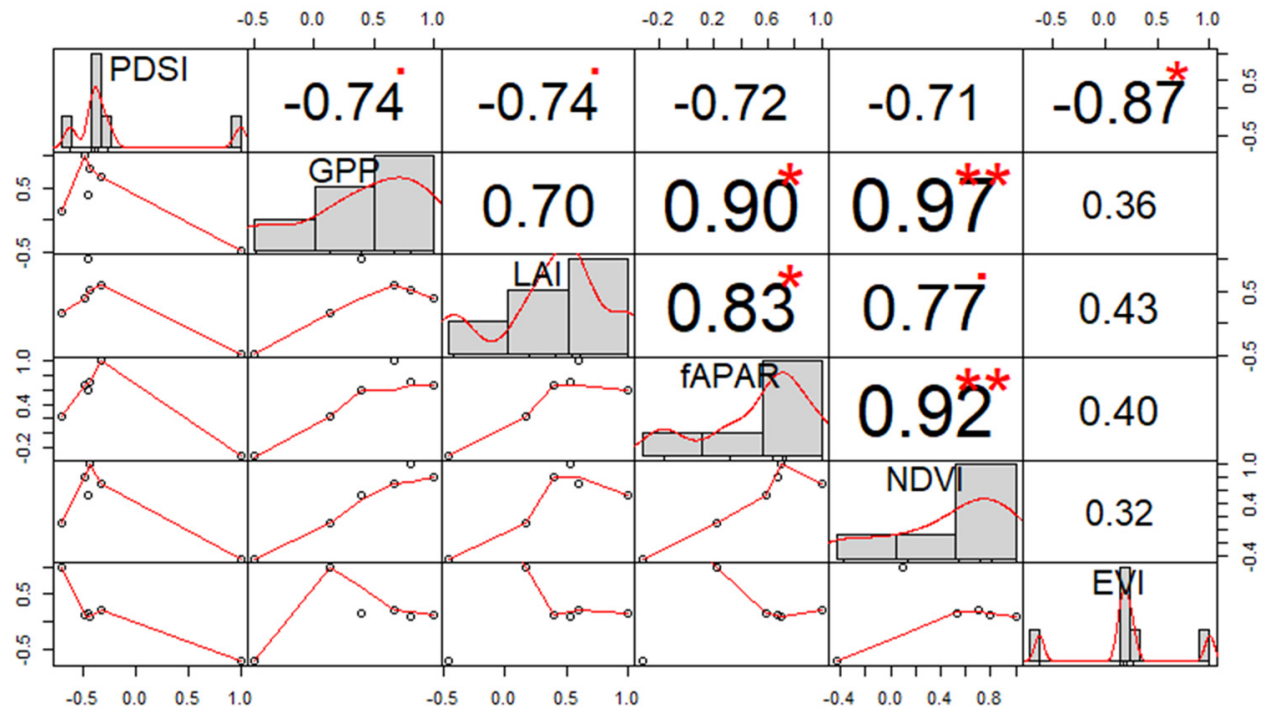

(b)

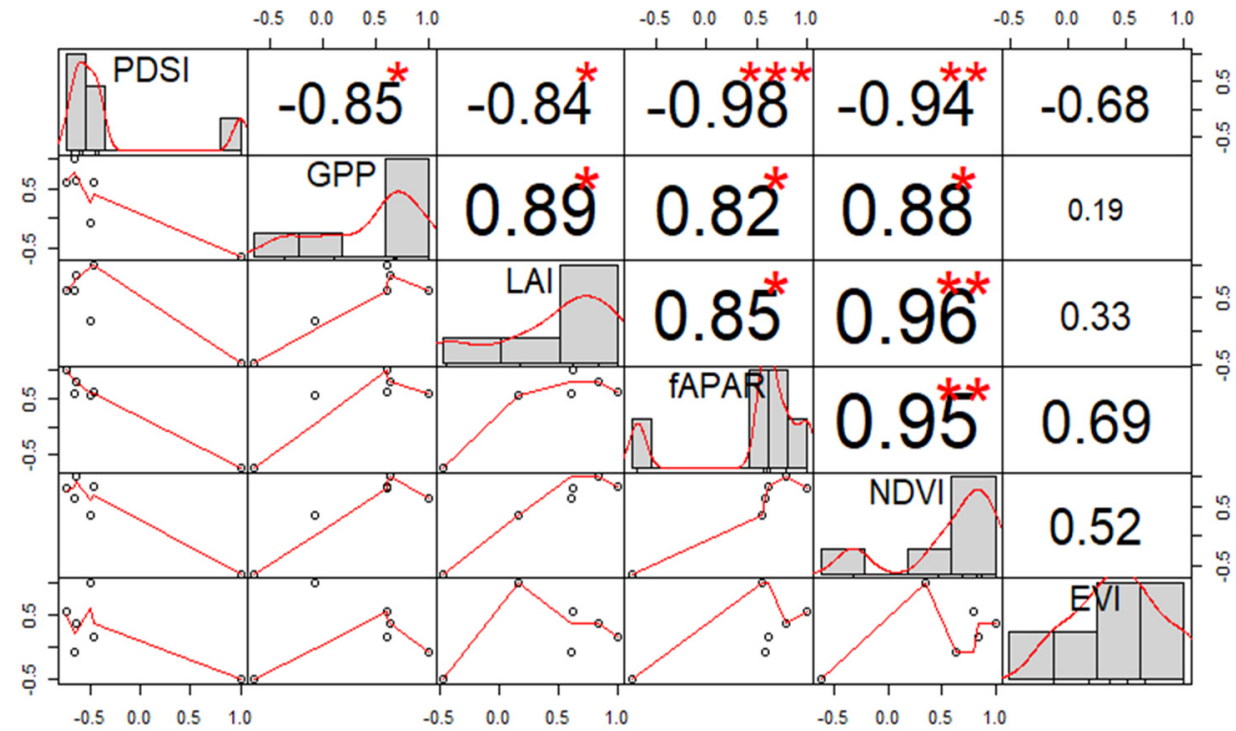

(c) 


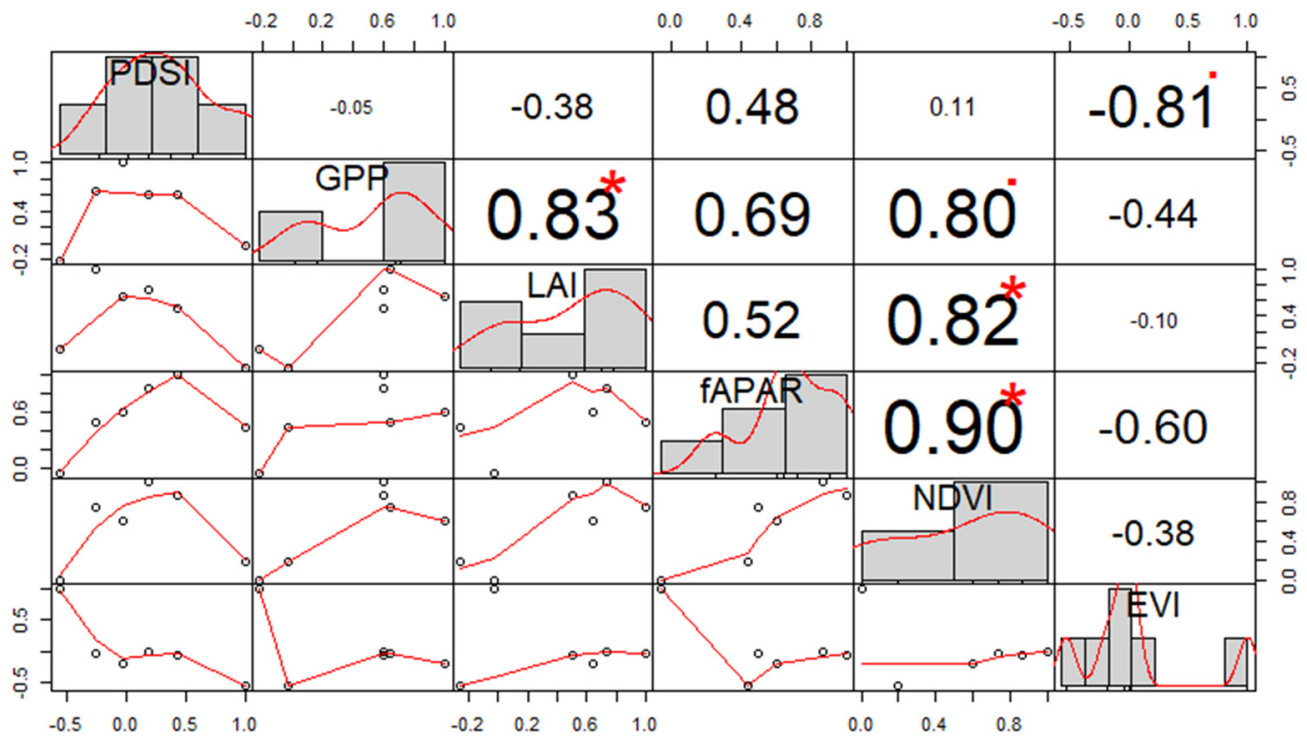

(d)

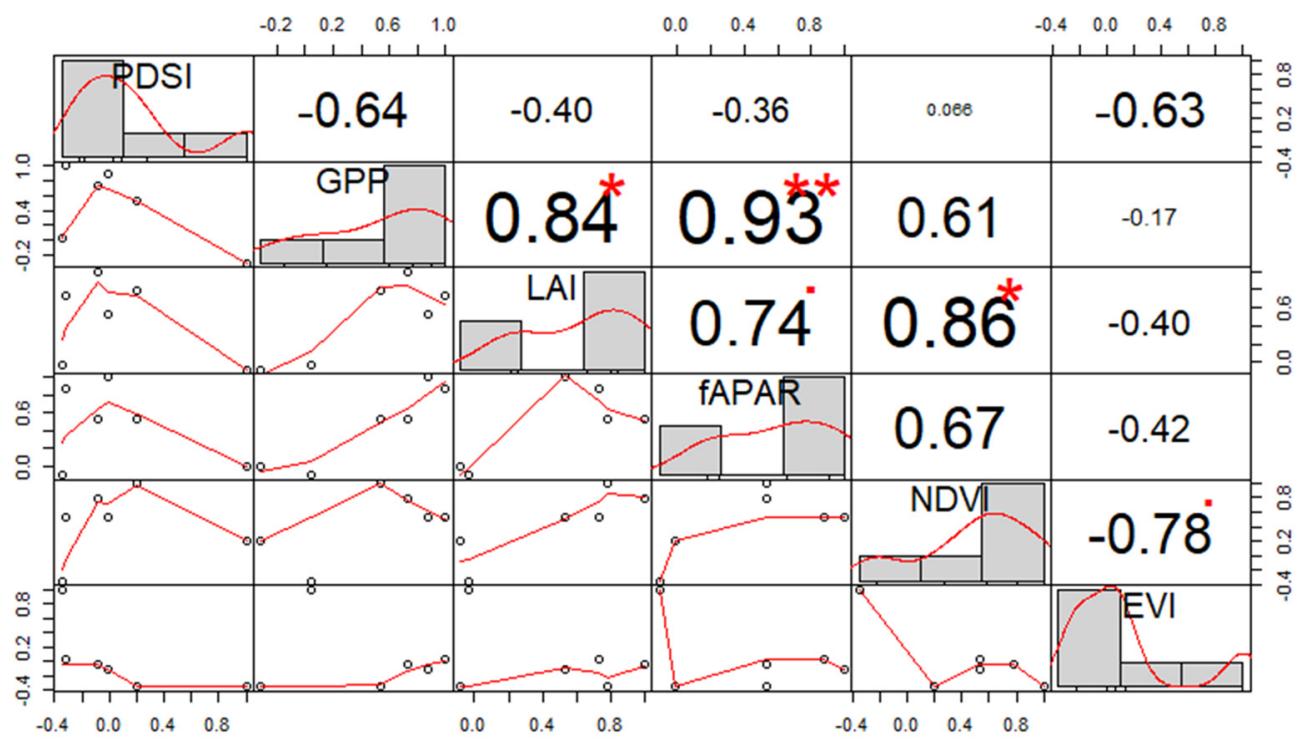

(e)

Figure 3. Correlation of the vegetation parameters with the PDSI in the years 2015 (a), 2016 (b), 2017 (c), 2018 (d), and 2019

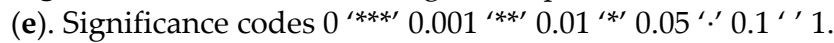

\subsection{Interpretation of Error Estimation Analysis}

The following table (Table 1) shows the calculated standard error values between the PDSI and vegetation parameters during 2015-2019 that were under consideration. The results showed that the estimated errors ranged from 70.10 to 105.98 between GPP and PDSI, 11.23 to 18.01 between LAI and PDSI, 9.07 to 18.11 between fAPAR and PDSI, 0.18 to 0.26 between NDVI and PDSI, and 0.07 to 0.12 between EVI and PDSI. EVI continuously managed to show the least estimated standard error values for all five years, clearly indicating the highest level of long-term sensitivity compared to the other parameters. The low error values between EVI and PDSI showed the most accurate negative agreement in all five years and, also, better represented the sensitivity compared to the NDVI, LAI, GPP, and fAPAR. 
Table 1. Calculated Standard Error of the Estimate between the Palmer Drought Severity Index (PDSI) and other vegetation parameters. GPP: Gross Primary Productivity, LAI: Leaf Area Index, fAPAR: fraction of absorbed Solar Radiation, NDVI Normalized Difference Vegetation Index, and EVI: Enhanced Vegetation Index.

\begin{tabular}{cccccc}
\hline YEAR & PDSI-GPP & PDSI-LAI & PDSI-fAPAR & PDSI-NDVI & PDSI-EVI \\
\hline 2019 & 70.10047 & 11.23408 & 16.35537 & 0.22529 & 0.07128 \\
2018 & 85.00281 & 14.707568 & 14.64304 & 0.26018 & 0.07962 \\
2017 & 84.30856 & 14.99181 & 9.07160 & 0.18792 & 0.12114 \\
2016 & 105.98472 & 18.01153 & 18.11280 & 0.21312 & 0.07426 \\
2015 & 97.12000 & 12.47910 & 16.85542 & 0.21665 & 0.11117 \\
\hline
\end{tabular}

\subsection{Interpretation of Uncertainty Analysis}

Both the EVI and NDVI showed the least uncertainties compared to the other vegetation parameters in respect to the PDSI for all five years (Figure 4). The RMSE values for both NDVI and EVI were found to range from $2.39 \%$ to 3.01\% during 2015-2018, which is, overall, the lowest among the others. However, in 2019, the NDVI showed slightly lesser RMSE values than EVI, but in that year, it was fAPAR that actually showed the optimum sensitive condition to the PDSI with a RMSE of $1.89 \%$. Overall, the estimated uncertainties (RMSE) between the PDSI and EVI and and PDSI and NDVI were found to be $1 \%$ to $2 \%$ lower compared to the others, showing better sensitivity than the other four vegetation parameters in a long-term context.

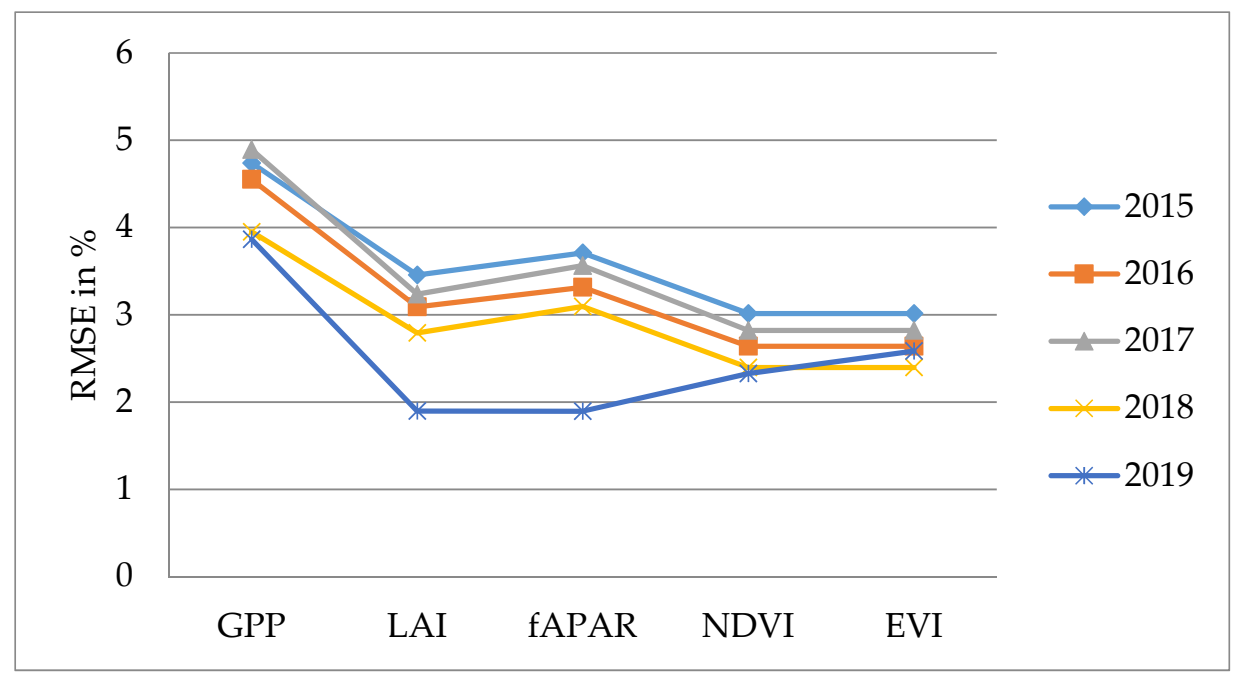

Figure 4. Uncertainty analysis (Root Mean Squared Error (RMSE)) of the vegetation parameters with the PDSI. GPP: Gross Primary Productivity, LAI: Leaf Area Index, fAPAR: fraction of absorbed Solar Radiation, NDVI Normalized Difference Vegetation Index, and EVI: Enhanced Vegetation Index.

\subsection{Sensitivity Ranking for the PDSI}

In compilation of the overall statistical analyses, such as agreement, error estimation, and uncertainty analysis, it was found that the EVI, which indicates the biomass of vegetation while ignoring the soil background and atmospheric effects, showed the most promising result in terms of long-term sensitivity to the PDSI in all five years (Table 2). However, it was also observed that the NDVI (greenness indicator) showed an overall similar result to the EVI in the uncertainty analysis and gave values very near to the EVI in the error estimation analysis. Though the NDVI could not outperform the EVI in the overall context, its sensitivity remained pretty impressive throughout the analyses, making NDVI the second-most sensitive vegetation parameter after the EVI, according to the study. Table 2 shows the best performances of vegetation parameters in all three sta- 
tistical analyses. Detailed results of the three statistical analyses are provided in the Appendix (See Table A1 of Appendix A).

Table 2. Compilation of the outcomes of the correlation, error estimation, and uncertainty analysis.

\begin{tabular}{cc}
\hline Analysis & Overall Most Sensitive Parameters \\
\hline Pearson's Correlation & EVI \\
Error Estimation & EVI \\
Uncertainty & NDVI, EVI \\
\hline
\end{tabular}

\section{Conclusions}

Based on the long-term analysis from this experimental study over the subtropical forest region of the Arunachal Pradesh state of India, it was observed that the EVI was the most sensitive parameter to the PDSI in a long-term observation based on promising correlation, low uncertainty, and low error, where most of the existing studies on drought severity showed a high sensitivity of GPP and NDVI in determining drought conditions. It is, therefore, stated that the EVI is the simple, effective, and most complementary indicator (among the vegetation parameters) for assessing the PDSI over forest regions of a tropical ecosystem. Besides, the EVI can also be used as a promising tool for the effective evaluation of long-term drought impacts on a forest ecosystem that indicates actual water deficit-induced stress conditions. In other words, the EVI can also act as a direct proxy of the actual drought conditions of the region. Similarly, after the EVI, the NDVI can be considered as the next promising sensitive indicator that is highly responsive to the PDSI. In future studies, more advanced vegetation parameters like Sun-induced fluorescence or SIF [25] can be added for PDSI-based drought monitoring. The authors assumed that this study will support sustainable forest management practices and drought monitoring under climate change scenarios for tropical ecosystems.

Author Contributions: Conceptualization, S.B.; methodology, S.B. and S.G.; software, S.B., S.G., and D.A.C.S.; validation, S.B., S.G., and D.A.C.S.; formal analysis, S.B. and S.G.; investigation, S.B., S.G., and D.A.C.S.; resources, S.B. and S.G.; data curation, S.B. and S.G.; writing-original draft preparation, S.G.; writing-review and editing, S.B. and D.A.C.S.; visualization, S.B. and S.G.; and project administration, S.B. All authors have read and agreed to the published version of the manuscript.

Funding: Analyses of the data were supported by the Polish National Research Centre (NCN) within the Project Sun Induced florescence and photosynthesis of the peatland vegetation response to stress caused by water deficits and increased temperature under conditions of climate manipulation experiment (No. 2016/21/B/ST10/02271).

Data Availability Statement: Derived data supporting the findings of this study are available from the corresponding author $[\mathrm{SG} / \mathrm{SB}]$ on request.

Acknowledgments: We sincerely appreciate the anonymous reviewers and members of the editorial team for their valuable comments and suggestions.

Conflicts of Interest: The authors declare no conflicts of interest.

\section{Appendix A}

Table A1. Statistical outcomes of 2015-2019.

\begin{tabular}{cccccccccccccccc}
\hline \multirow{2}{*}{ Parameters } & \multicolumn{4}{c}{ 2015 } & \multicolumn{4}{c}{ 2016 } & \multicolumn{2}{c}{ 2017 } & \multicolumn{2}{c}{ 2018 } & \multicolumn{2}{c}{ 2019 } \\
& r & SEE RMSE (\%) & r & SEE & RMSE (\%) & r & SEE & RMSE (\%) & r & SEE RMSE (\%) & r & SEE RMSE (\%) \\
\hline GPP & -0.86 & 97.12 & 4.73 & -0.74 & 105.98 & 4.55 & -0.85 & 84.3 & 4.89 & -0.05 & 85 & 3.95 & -0.64 & 70.1 & 3.86 \\
LAI & -0.74 & 12.47 & 3.45 & -0.74 & 18.01 & 3.09 & -0.84 & 14.99 & 3.23 & -0.38 & 14.7 & 2.79 & -0.4 & 11.23 & 1.89 \\
fAPAR & -0.91 & 16.85 & 3.7 & -0.72 & 18.11 & 3.31 & -0.98 & 9.07 & 3.56 & 0.48 & 14.64 & 3.09 & -0.36 & 16.35 & 1.89 \\
NDVI & -0.93 & 0.21 & 3.01 & -0.71 & 0.21 & 2.63 & -0.94 & 0.18 & 2.82 & 0.11 & 0.26 & 2.39 & 0.066 & 0.22 & 2.32 \\
EVI & 0.5 & 0.11 & 3.01 & -0.87 & 0.07 & 2.63 & -0.68 & 0.12 & 2.82 & -0.81 & 0.07 & 2.39 & -0.63 & 0.07 & 2.58 \\
\hline
\end{tabular}




\section{References}

1. Palmer, W.C. Meteorological Drought; Research Paper No. 45; U.S. Weather Bureau: Washington, DC, USA, 1965.

2. Guttman, N.B.; Wallis, J.R.; Hosking, J.R.M. Spatial Comparability of the Palmer Drought Severity Index. J. Am. Water Resour. Assoc. 1992, 28, 1111-1119, doi:10.1111/j.1752-1688.1992.tb04022.x.

3. Graw, V.; Ghazaryan, G.; Dall, K.; Gómez, A.D.; Abdel-Hamid, A.; Jordaan, A.; Piroska, R.; Post, J.; Szarzynski, J.; Walz, Y.; et al. Drought dynamics and vegetation productivity in different land management systems of Eastern Cape, South Africa-A remote sensing perspective. Sustainability 2017, 9, 1728, doi:10.3390/su9101728.

4. Wang, H.; He, B.; Zhang, Y.; Huang, L.; Chen, Z.; Liu, J. Response of ecosystem productivity to dry/wet conditions indicated by different drought indices. Sci. Total Environ. 2018, 612, 347-357, doi:10.1016/j.scitotenv.2017.08.212.

5. Xie, X.; Li, A.; Tan, J.; Lei, G.; Jin, H.; Zhang, Z. Uncertainty analysis of multiple global GPP datasets in characterizing the lagged effect of drought on photosynthesis. Ecol. Indic. 2020, 113, 106224, doi:10.1016/j.ecolind.2020.106224.

6. Ciais, P.; Reichstein, M.; Viovy, N.; Granier, A.; Ogée, J.; Allard, V.; Aubinet, M.; Buchmann, N.; Bernhofer, C.; Carrara, A.; et al. Europe-wide reduction in primary productivity caused by the heat and drought in 2003. Nature 2005, 437, 529-533, doi:10.1038/nature03972.

7. He, M.; Kimball, J.S.; Running, S.; Ballantyne, A.; Guan, K.; Huemmrich, F. Satellite detection of soil moisture related water stress impacts on ecosystem productivity using the MODIS-based photochemical reflectance index. Remote Sens. Environ. 2016, 186, 173-183, doi:10.1016/j.rse.2016.08.019.

8. Yu, Z.; Wang, J.; Liu, S.; Rentch, J.S.; Sun, P.; Lu, C. Global gross primary productivity and water use efficiency changes under drought stress. Environ. Res. Lett. 2017, 12, doi:10.1088/1748-9326/aa5258.

9. Vicca, S.; Balzarolo, M.; Filella, I.; Granier, A.; Herbst, M.; Knohl, A.; Longdoz, B.; Mund, M.; Nagy, Z.; Pintér, K.; et al. Remotely-sensed detection of effects of extreme droughts on gross primary production. Sci. Rep. 2016, 6, 1-13, doi:10.1038/srep28269.

10. Zhao, M.; Running, S.W. Drought-Induced Reduction in Global Terrestrial Net Primary Production from 2000 Through 2009. Science 2010, 329, 940-943, doi:10.1126/science.1192666.

11. Zscheischler, J.; Reichstein, M.; Harmeling, S.; Rammig, A.; Tomelleri, E.; Mahecha, M.D. Extreme events in gross primary production: A characterization across continents. Biogeosciences 2014, 11, 2909-2924, doi:10.5194/bg-11-2909-2014.

12. Zhang, L.; Qiao, N.; Huang, C.; Wang, S. Monitoring Drought Effects on Vegetation Productivity Using Satellite Solar-Induced Chlorophyll Fluorescence. Remote Sens. 2019, 11, 378, doi:10.3390/rs11040378.

13. Diodato, N.; Bellocchi, G. Modelling vegetation greenness responses to climate variability in a Mediterranean terrestrial ecosystem. Environ. Monit. Assess. 2008, 143, 147-159, doi:10.1007/s10661-007-9964-z.

14. Gu, Y.; Hunt, E.; Wardlow, B.; Basara, J.B.; Brown, J.F.; Verdin, J.P. Evaluation of MODIS NDVI and NDWI for vegetation drought monitoring using Oklahoma Mesonet soil moisture data. Geophys. Res. Lett. 2008, 35, L22401, doi:10.1029/2008GL035772.

15. Brown, J.F.; Wardlow, B.D.; Tadesse, T.; Hayes, M.J.; Reed, B.C. The Vegetation Drought Response Index (VegDRI): A New Integrated Approach for Monitoring Drought Stress in Vegetation. GISci. Remote Sens. 2008, 45, 16-46, doi:10.2747/1548-1603.45.1.16.

16. Peters, A.J.; Walter-Shea, E.A.; Ji, L.; Viña, A.; Hayes, M.; Svoboda, M.D. Drought monitoring with NDVI-based Standardized Vegetation Index. Photogramm. Eng. Remote Sens. 2002, 68, 71-75.

17. Rousta, I.; Olafsson, H.; Moniruzzaman, M.; Zhang, H.; Liou, Y.A.; Mushore, T.D.; Gupta, A. Impacts of drought on vegetation assessed by vegetation indices and meteorological factors in Afghanistan. Remote Sens. 2020, 12, 2433, doi:10.3390/RS12152433.

18. Wang, P.X.; Wan, Z.M.; Gong, J.Y.; Li, X.W.; Di, W.J. Advances in drought monitoring by using remotely sensed normalized difference vegetation index and land surface temperature products. Adv. Earth Sci. 2003, 18, 527-533.

19. Chen, W.; Xiao, Q.; Sheng, Y. Application of the Anomaly Vegetation Index to Monitoring Heavy Drought in 1992. J. Remote Sens. 1994, 9, 106-112.

20. Forest Survey of India. India State of Forest Report 2019; Forest Survey of India (Ministry of Environment, Forest \& Climate Change, Government of India): Dehradun, India, 2019; Volumes I and II; ISBN 9788194101802.

21. Abatzoglou, J.T.; Dobrowski, S.Z.; Parks, S.A.; Hegewisch, K.C. TerraClimate, a high-resolution global dataset of monthly climate and climatic water balance from 1958-2015. Sci. Data 2018, 5, 170191, doi:10.1038/sdata.2017.191.

22. Martinović, M.; Stoić, M.; Duspara, M.; Samardžić, I.; Stoić, A. Algorithmic conversion of data displayed on a weekly basis to the monthly level using the spreadsheet. Procedia Eng. 2016, 149, 288-296, doi:10.1016/j.proeng.2016.06.669.

23. McHugh, M.L. Standard error: Meaning and interpretation. Biochem. Medica 2007, 17, 7-13.

24. PTI Heavy Rains Trigger Flood-Like Situation in Arunachal Pradesh. Available online: https:/economictimes.indiatimes.com/ news/politics-and-nation/heavy-rains-trigger-flood-like-situation-in-arunachal-pradesh/articleshow/48743001.cms (accessed on 5 October 2020).

25. Bandopadhyay, S.; Rastogi, A.; Juszczak, R. Review of Top-of-Canopy Sun-Induced Fluorescence (SIF) Studies from Ground, UAV, Airborne to Spaceborne Observations. Sensors 2020, 20, 1144, doi:10.3390/s20041144. 